\title{
A new framework for modelling seed germination and seedling tillering of winter wheat in the field
}

\author{
Jinping Chen ${ }^{1}$, Peter Whalley ${ }^{2}$, Yang $\mathrm{Gao}^{3}$, xiaoxian zhang ${ }^{4}$, Malcolm J. Hawkesford ${ }^{4}$, \\ and richard whalley ${ }^{5}$ \\ ${ }^{1}$ Chinese Academy of Agricultural Sciences \\ ${ }^{2}$ University of Edinburgh \\ ${ }^{3}$ Farmland Irrigation Research Institute, Chinese Academy of Agricultural Sciences, \\ ${ }^{4}$ Rothamsted Research \\ ${ }^{5}$ Rothamsted Research
}

October 17, 2021

\begin{abstract}
Seed germination is regulated by multiple environmental cues and understanding their relationships is critical to planning seed drilling and subsequent seedling management. We develop a new framework by viewing the metabolic reactions associated with seed germination as a moving event in a physiological dimension to simulate seed germination. Fluctuations in environmental cues and genetic heterogeneity of seed lot make the metabolic reactions in each seed uncertain, and we use an average germination rate to describe the average metabolic reactions and a dispersion coefficient to describe the genetic heterogeneity. We apply the model to winter wheat seeds drilled at different dates in plots under different soil water contents and prove that the model accurately reproduces the time course of germination in all treatments. We found the average germination rate increases nonlinearly with temperature in the base-suboptimal temperature range, and there is an optimal soil water content where the germination rate peaks due to soil anaerobicity. Our model can be fitted to field data using temperature and soil water content to describe the trade-off impact of soil water on soil anaerobicity and imbibition, whereas the difficulty of obtaining accurate water potential and oxygen measurements makes this difficult with the hydrothermal time models.
\end{abstract}

\section{Hosted file}

Germination_v1 wrw_mjh_0.docx available at https://authorea.com/users/441538/articles/542023a-new-framework-for-modelling-seed-germination-and-seedling-tillering-of-winter-wheatin-the-field 